\title{
Using English in presentation skills for personal and professional endeavors in the multicultural setting
}

\author{
Naveen Kumar Mehta*, Dharmendra Mehta** \\ *Sanchi University of Buddhist-Indic Studies, Barla, India; nknmehta@gmail.com \\ **Vikram University, Ujjain, India; shardadnm28@gmail.com
}

\begin{abstract}
Presentation skill is an art that can enable the professionals to scale new heights of excellence in their work stations. Presentation demands thorough understanding of the talk, strategic planning, awareness about the audience, good hold on voice modulation, and adequate knowledge about non-verbal cues, judicious use of multi-media, time management, and mastery over communication, active listening, and good reading habits. Language indubitably is a very instrumental in translation ideas into words. The methodology adopted for the entire elucidation is conceptual one in which research is conducted by observing and analyzing the problem. The paper is based on secondary information collected through personal interviews, research papers, related websites, journals and magazines. The secondary data here implies a close review of previously collected data in the area of present research study. The study presents a conceptual model so as to use English as a link language for effective presentation skills in exploring personal and professional opportunities. Only a few empirical research studies have been attempted in this context and highlighted that presentation skills are integrated part of employability kills and therefore transferable in nature, can be taught and could be a key factor for employment along with personal and professional growth in multicultural settings. Use of English as a lingua franca enables the users to develop presentation skills to work collaboratively with professionals from nation, cultural and linguistic background.
\end{abstract}

Keywords: presentation, professional, communication, language, education, management

\section{Introduction}

The professional skills are matter of fact a set of advance level of communication skills. In communication skills, presentation skills play a paramount role to transfer the information and knowledge in an effective and better manner. In the globalized context, the organizations prefer to have professionals who hold a good command over the art of presentation skills. The importance of presentation skills is growing immensely as it is required during conferences/workshops/lectures/seminars/meetings/negotiations etc. Presentation plays a pivotal role to convey the concepts in a comprehensive way. The presenters should make serious efforts to achieve the set personal and professional goals. The key to become successful presenter largely looms upon practice and then present it with confidence and clarity before audience.

The presentation cannot be put in isolation as audience's interest and role is quite broad to determine the objective of any presentation. Presentations have become essential attain success at personal and professional fronts. Thus, students' presentations is an important element in delivering positive learning experiences and are important part of professional environment, as professionals need to communicate with other professionals at meetings, seminars, conferences. So, designing effective oral presentations is the need of the hour. Improving the quality of presentation actually improves the quality of thought, and vice versa. Training and Learning of Presentation skills are directly or indirectly associated with employability skills. It is said that "practice makes perfect" and it appears true in the context of presentation skills. The modern day organizations know well that they can make profit out of the added value employees with excellent presentation skills who can actively and successfully contribute finalizing business deals, solving problems of customer and by strengthening customer relationship, by developing team and organizing efficient team meetings etc.

In this backdrop, at the global platform, English is not only an international language but essential language for interpersonal communication. It helps people of various ethnic linguistic groups to be 
united. At the global platform, using English can make significant contribution towards shaping multicultural awareness. English language is important to communicate with people from other cultures. By applying multicultural perspective while using English language, the presenter will obtain knowledge, and skills needed to function within his/her own culture, mainstream cultural and the global community.

\section{Research methodology and objective(s)}

The paper is based on secondary information collected through personal interviews, research papers, related websites, journals and magazines. The secondary data here implies a close review of previously collected data in the area of present research study. The Paper offers a conceptual framework and a conceptual model so as to use English for effective presentation skills and thereby present paper focuses on using English for effective presentation skills in exploring personal and professional opportunities in multicultural business environment in order to develop a very congenial work station.

\section{Literature review}

There has not been much research on importance and impact of presentation skills for personal and professional growth. Some of the noteworthy contributions have been discussed here as:

King (2002) revealed that presentations offer an opportunity for developing communication as well as leadership skills. Carroll (2005) opinioned that the presentation should include elements that need to be assessed like as knowledge shown, logical appeal, fielding of objections, questions posed, improvisation shown, and conclusion.

Carroll (2006) advocated a holistic approach in assessing a student's performance based on the content and the delivery of their presentation. Kennedy (2007) found that through organization of debate, teachers can cultivate both critical thinking and oral communication skills. Bankowski (2010) found that training students in skills is very important for making oral presentations based on original research task for using English for Academic Purposes (EAP) course and after training students showed an increase in the successful use of research related skills and a great improvement in their ability to present their findings in English. Girard and Trapp (2011) expressed that presentation skills help in greater class interaction and participation, increased interest in learning, new perspectives not covered otherwise and improvement in communication and presentation skills.

Živković and Stojković (2013) viewed that the ultimate purpose of a well-balanced presentation is to better communicating professional knowledge to other professionals and to non-specialists as well.

Alwi and Sidhu (2013) studied students' self-perceived and actual performance in attempting oral presentations. The study employed a mixed method research design and involved an intact class of 40 Business Faculty undergraduates taking an ESL course in a local university in Malaysia. The results of the study indicated that there were discrepancies between the actual performance scores and students' selfevaluation marks for all the four skills hence it is necessary for educators to understand these discrepancies and work towards further understanding their students' learning needs.

Živković (2014) said that the effective oral presentations has primarily two goals, first enabling students to function successfully in the future professional surrounding, and preparing them for their possible further academic career. Kaltenbach and Soetikno (2016) opined that there are many factors that help to develop an effective presentation such as by becoming focused, clear and visual with the content, and by providing variance, relevance, and emotion in the delivery.

Imam and Alalyani (2017) showed that students perceived the significance of preparing and delivering oral presentations for successful communication in the future professional surrounding. The study also found that through collaboration with their colleagues, students develop skills that prepare them to deal with situations and problems they will encounter in the workplace. Dolan (2017) remarked that presentation skills are very essential in every aspect of academic/business life, from meetings, interviews and conferences to trade shows and job fairs and further he pointed out that there are three key 
components of a good presentation as structure, introduction, content and conclusion, body language and movement and verbal delivery. Anita (2017) examined the issues, challenges, and opportunities in English language learning and identity trans-formation in the multicultural context of Indonesia.

Liang and Kelsen (2018) investigated the oral performance of EFL students engaged in delivering presentations required as part of inquiry-based group projects and found that $t$ Extraversion, Project Work and Social Pressure were significant correlates of oral presentation scores.

According to Businesstopia (2019) developing presentation skills makes communication effective as it nurtures personality of individuals. Miskam, Aminabibi and Saidalvi (2019) explored the effectiveness of using Flipgrid, an online video-mediated communication tool, for teaching oral presentation skills to engineering students. By application of this tool, students can record and practice oral presentation skills and can have prompt feedback. The results indicated that Flipgrid helped the students to practice oral presentation skills.

\section{Using English for presentation skills}

It is a matter of fact that the United Nations has recognized five languages as its official languages and of them English holds the first position due to its international acclaim of easy access to the masses. English is playing a pivotal role in all the branches of learning and knowledge. English has become the lingua franca of the world in the fields of business, science, aviation, computing, education, politics and entertainment. The importance of the ability to speak or write English has recently increased significantly because English has become the de facto standard. Good command over English language is the most important requirements in many professions. This is why one should learn English by using it in wellstructured and thoroughly prepared presentation one can explore plethora of global opportunities. Knowing and using English will be a huge advantage as it enables one to communicate with people from many different parts of the world.

Speaking English fluently and with confidence will surely open plethora of job opportunities such as in call centers, meeting foreign delegates, presenting projects to international or multinational companies. Use of English as a language during oral presentation is inevitable as It is the language of international business and trade, it helps to understand other languages, it is the language of higher studies, research, medicine, science, technology, and library, it is flexible and has a very rich vocabulary, it is widely used, easy and very powerful tool of communication during cross cultural communication. But it is quite unfortunate to note that no serious attempts are being made by the academic institutions to sharpen the latent skills of the learners so as to make them employable to face the stiff competitive market. English has achieved the status of a second language for majority of people across the globe. It is a universally accepted language. About 380 million people regard English as their first language; two thirds of them prefer it as a second language. It is often predicted that by 2050, half the world's population will be trained in English. Hence, it is important to know how English language will unite people. English is also very necessary to the field of education. In many countries, children are taught and encouraged to learn English as a second language as almost 90\% educational subjects are written in English.

This fact is also resulted in a study conducted by Sapp and Zhang (2000) in which a survey among 238 industry supervisors over a 5-year-period in the departments of English and communication at a private university in the Northeast was conducted and they revealed that rarely do university faculties have the chance to incorporate practical pieces of advice and guidance from business partners and industry insiders into their courses, aiming to facilitate students' transition into full-time employment. This study is an eye opener as it clearly indicates that there is big mismatch between what students learnt in the name of soft skills and what corporate world expects from them to deliver. Hence, it is high time for academician, trainers, researchers and institutions to work upon the communication skills and especially on presentation skills of the learners so they can excel in their respective endeavors. 
Figure 1: Importance of English for effective presentation skills.

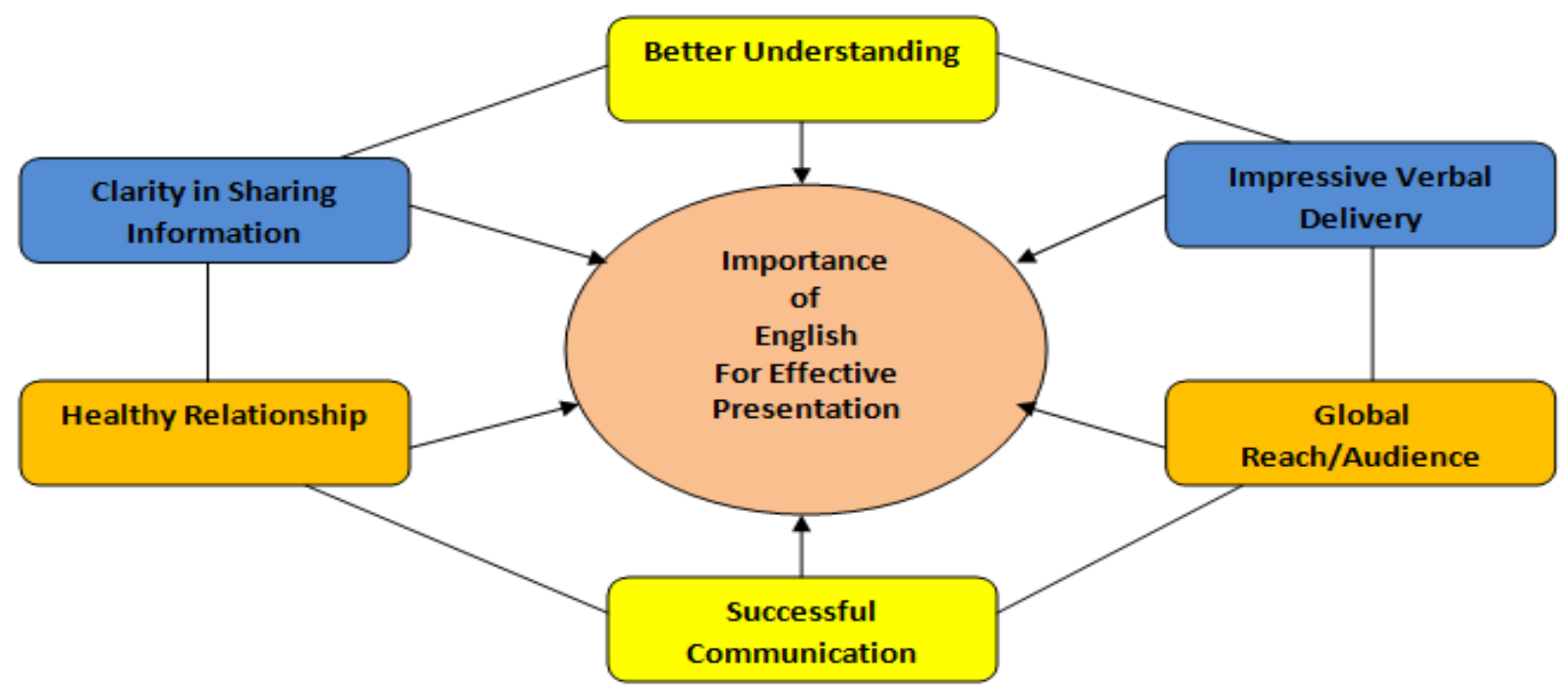

Source: Developed by the authors on the basis of literature review

English is the easiest language of the world to learn as there are plenty of resources available. Role of English as a language is very crucial and therefore a presenter must be careful to use it flawless. It is strongly advisable that one should use spoken rather than written English. A good presenter will take care of following as:

- Use active rather than passive verbs;

- Avoidance of technical terms, if audience is familiar than think about usages;

- Always use simple and known words and phrases;

- Avoid jargon/slang words;

- Distinguish between denotative or connotative meanings;

- Change pace or volume, use a longer than normal pause between key points and change pitch or inflection;

- Avoid common mistakes of spellings, stress, intonation, pronunciations, and sentence constructions;

- Avoid speaking at fast speed as it hinders the audience comprehension;

- It is very necessary to avoid stress on unimportant words clouds meaning, poor phrasing, and putting pauses in the wrong places;

- Word choice must be simpler, more informal, and more repetitive as written language uses a larger vocabulary and is more formal;

- It is better to use short words and short sentences and talk about concrete facts rather than abstract ideas;

- It is advisable that one should rehearse a test run in front of a mirror, demonstrate presentation for a friend and use IT enabled technologies to record, listen/view and improve it;

- Use indirect narration to express and extend view points;

- Have clarity in listening questions from audience and avoid ambiguity in answering questions.

Table 1: Main usages of English as a language for conducting various activities @ presentation. 


\begin{tabular}{|c|c|}
\hline Activities & Usages of Language \\
\hline Introducing the topic & $\begin{array}{ll}\text { - } & \text { I'd like to begin by... } \\
\text { - } & \text { Let's begin by... } \\
\text { - } & \text { First of all, I'll... } \\
\text { - } & \text { Starting with... } \\
\text { - } & \text { I'll begin by.. } \\
\text { - } & \text { At the outset....... }\end{array}$ \\
\hline For Giving an example & $\begin{array}{l}-\quad \text { For example,... } \\
\text { - } \quad \text { A good example of this is... } \\
\text { - } \quad \text { To give you an example,... }\end{array}$ \\
\hline Dealing with questions & $\begin{array}{l}\text { - I'd like to deal with this question later, if I may... } \\
\text { - } \quad \text { I'll come back to this question later in my talk... } \\
\text { - } \quad \text { I won't comment on this now... }\end{array}$ \\
\hline Summarizing and concluding & $\begin{array}{ll}\text { - } & \text { In conclusion... } \\
\text { - } & \text { Right, let's sum up, shall we? } \\
\text { - } & \text { I'd like now to recap... } \\
\text { - } & \text { Let's summarize briefly what we've looked at... } \\
\text { - } & \text { Last but not the least........ }\end{array}$ \\
\hline
\end{tabular}

Source: Based on literature review

\section{Proposed activities for effective presentation skills}

On the basis of literature review, following classroom activities are proposed as:

Activity: I

This activity is a group activity. Divide the class into small groups. Assign different sections to each member like as Introduction, Main Portion-Central Idea and Conclusion on the selected topics such as Importance of Communication Skills, Education and Civilization etc. Ask the other groups to provide feedback on account of Communication, Content, Delivery, Use of Verbal and Non Verbal Language etc. Time duration for each student will be 05 minutes. This activity can be conducted at the Junior College level.

\section{Activity: 2}

This activity is based on role play. Organize a Mock Seminar or Conference in the classroom. Assign students roles such as Chairperson, Keynote Speaker, Experts, Observers, Evaluators, Participants, Repertoire and as members of organizing committee. Some students will be given topics of presentation well in advance and will deliver their presentation before the class. Time duration for each student will be 10 minutes. This activity can be conducted at the University level.

\section{Concluding remarks}

Language allows us to recall the past, deal with the present, and plan for the future. Language helps us to know how a culture perceives reality. English language competence could be developed to be a tool for promoting intercultural communication in organizations. Harris and Sherblom (2011) remarked that diversity in language, culture, background, and values seem to affect small group communication in the working place. In an era of globalization and privatization, only English as a 
global language can easily meet all the challenges of the growing demands. The success of an effective oral presentation lies in preparation, planning and organization. A presenter has to be very particular in selecting appropriate words and there should not be any ambiguity in usages. The tone should have a combination of rising and falling tone, pitch should be variable, accent should have accuracy, speed should be maintained, pronunciation should be refined, pauses should be used aptly, and top of all variation in voice modulation should be monitored closely.

Effective presentation skills are integral part of successful communication as it supports to communicate more effectively and professionally with audience, employer, team members, students, teachers and all others. It is very popular as it is meaningful, inspirational, creative, memorable and informational. Since presentation is executed in the global settings so English as a link language is the only and best medium of effective and successful communication. For a well-structured, planned and executed presentation, English will remain as the most popular language for many years to come as it has a wide access to a broader range of information, connections, and opportunities.

By using English as a global language, positive intergroup attitudes among the presenters from different racial, cultural, language, and social- class groups can be developed for personal and professional growth. "No language can exists unless it is steeped in the context of culture; and no culture can exists which does not have at its center, the structure of natural language." (Tirumalesh, 1999) Language diversity of English as a language can potentially provide presenters with competitive advantages over others. Effective presentation skills can translate better performance into grand success at multicultural and multilingual workplace. Therefore, undoubtedly, English as a language will remain as the most influential key to open the channel of effective communication in any sort of presentation.

\section{Acknowledgement}

The Presenters are extremely thankful to the Organizing Committee of ERLIV, especially to conference coordinators Dr. Michał Daszkiewicz and Dr. Monica Tilea for their continuous support and generosity to pen down the present paper in print form.

\section{References}

Alwi, N. F. B. \& Sidhu, G. K. (2013). Oral Presentation: Self-perceived Competence and Actual Performance among UiTM Business Faculty Students. Procedia - Social and Behavioral Sciences, 90, 98-106.

Bankowski, E. (2010). Developing Skills for Effective Academic Presentations in EAP. International Journal of Teaching and Learning in Higher Education, 22 (2), 187-196.

Businesstopia (2019). Effective Communication Skills, Businesstopia, February 4, 2018, https://www.businesstopia.net/blog/effective-communication-skills. (10 April, 2019).

Carroll, C. (2005). Assessing Project-Based Learning: A Case Study of an Undergraduate Selling and Sales Management Module at the University of Limerick, in: T. Barrett, I. Mac Labhrainn, H. Fallon, H. (Eds), Handbook of Enquiry and Problem-based Learning. Galway: All Ireland Society for Higher Education, and Centre for Excellence in Learning and Teaching, NUI Galway, 95-102.

Carroll, C. (2006). Enhancing Reflective Learning through Role-Plays: The Use of an Effective Sales Presentation Evaluation Form in Student Role-Plays, Marketing Education Review, 16 (1), 9-13.

Dolan, R. (2017). Effective Presentation Skills, FEMS Microbiology Letters, 364 (24).

Girard, M. P. \& Trapp, P. (2011). An Exploratory Study of Class Presentations and Peer Evaluations: Do Students Perceive Benefits? Academy of Educational Leadership Journal, 15 (1), 77-94.

Gohain, M. P. (2019) "Boost English, says Draft Education Policy", The Times of India, 06 June, 2019 https://timesofindia.indiatimes.com/india/boost-english-says-draft-education-policy/articleshow/69669279.cms. (6 June, 2019).

Harris, T. \& Sherblom, J. (2011). Small Group and Team Communication. Boston: Pearson Allyn \& Bacon. 
Imam, S. A. \& Alalyani, M. (2017) Study of Significance of Oral presentation and its impacts on Students of College of Applied Medical Sciences, Khamis Mushait, King Khalid University, Kingdom of Saudi Arabia- A Pilot Study. Imperial Journal of Interdisciplinary Research, 3 (1), 1438-1442.

Kennedy, R. (2007). In-Class Debates: Fertile Ground for Active Learning and the Cultivation of Critical Thinking and Oral Communication Skills. International Journal of Teaching and Learning in Higher Education, 19 (2), $183-190$.

Kaltenbach, T. \& Soetikno, R. (2016). How to Create and Deliver an Effective Presentation. Gastroenterology, 151, 1058-1060.

King, J. (2002). Preparing EFL learners for Oral Presentations Preparing. Journal of Humanistic Studies, 4, $401-418$.

Liang, H.-Y. \& Kelsen, B. (2018). Influence of Personality and Motivation on Oral Presentation Performance. Journal of Psycholinguistic Research, 47 (4), 755-776.

Lie, A. (2017). English and Identity in Multicultural Contexts: Issues, Challenges, and Opportunities. Teflin Journal, 28 (1), 71-92.

Miskam, N. N. \& Aminabibi, S. (2019). The Use of Flipgrid for Teaching Oral Presentation Skills to Engineering Students. International Journal of Recent Technology and Engineering, 8 (1), 536-541.

Sapp, D. \& Zhang, Q. (2009). Trends in Industry Supervisor Feedback on Business Communication Internships. Business Communication Quarterly, 72 (3), 274-288.

Tirumalesh, K. V. (1999). Language Matters: Essay on Language, Literature and Translation. New Delhi: Allied Publishers Limited.

Živković, S. \& Stojković, N. (2013). To Modernize or not to Modernize - There is no Question. Academic Journal of Interdisciplinary Studies, 2 (11), 70-76.

Živković, S. (2014). The Importance of Oral Presentations for University Students. Mediterranean Journal of Social Sciences, 5 (19), 468-475. 